\title{
Atomic layer deposition on polymer thin films: on the role of precursor infiltration and reactivity
}

\author{
Robin R. Petit ${ }^{a, b, c}$, Jin Li ${ }^{b}$, Babs Van de Voorde ${ }^{d}$, Sandra Van Vlierberghe ${ }^{d}$, Philippe F. Smet ${ }^{a}$, Christophe \\ Detavernier $^{b^{*}}$ \\ ${ }^{a}$ Department of Solid State Sciences, LumiLab, Ghent University, Krijgslaan 281 S1, 9000 Gent, Belgium \\ ${ }^{b}$ Department of Solid State Sciences, CoCooN, Ghent University, Krijgslaan 281 S1, 9000 Gent, Belgium \\ ${ }^{c}$ SIM vzw, Technologiepark 48, 9052 Zwijnaarde, Belgium \\ ${ }^{d}$ Department of Organic and Macromolecular Chemistry, PBM, CMaC, Ghent University, Krijgslaan 281 \\ S4-Bis, 9000 Gent, Belgium \\ *E-mail: Christophe.Detavernier@UGent.be
}

\section{Supporting information}




\section{Determining TMA diffusion coefficients for PS, PMMA and PET-G}

Diffusion coefficients were determined to quantify the rate of the TMA infiltration into the PS, PMMA and PET-G thin films. A method to obtain diffusion coefficients for penetrants (TMA) in polymer thin films is outlined in [1,2], based on the work by Crank [3]. For the diffusion in a plane sheet, i.e. a polymer thin film the following expression is obtained:

$$
\frac{M_{t}}{M_{\infty}}=1-\frac{8}{\pi^{2}} \sum_{n=0}^{\infty} \frac{1}{(2 n+1)^{2}} \exp \left(\frac{-D(2 n+1)^{2} \pi^{2}}{L^{2}} t\right)
$$

Here is $\mathrm{M}_{t}$ the total infiltrated penetrant mass at a time $\mathrm{t}$, with $\mathrm{M}_{\infty}$ corresponding to saturation of the polymer thin film by the penetrant species, $\mathrm{D}$ is the diffusion coefficient and $\mathrm{L}$ is the thickness of the polymer layer. For very large times $t$, the second term in equation (1) becomes zero, yielding $\mathrm{M}_{t}=\mathrm{M}_{\infty}$ indicating the infiltration has reached saturation, i.e. the penetrant concentration inside the polymer thin film is equal to the penetrant concentration outside the polymer thin film and no further polymer swelling is obtained by extending the exposure of the polymer thin film to the penetrant species. For small t, while assuming that the observed polymer swelling $\mathrm{S}_{t}$ is linearly dependent on the amount of infiltrated penetrant $\mathrm{M}_{t}$, the following expression is obtained:

$$
\frac{M_{t}}{M_{\infty}} \approx \frac{S_{t}}{S_{s a t}}=\frac{4}{L}\left(\frac{D}{\pi}\right)^{\frac{1}{2}} t^{\frac{1}{2}}
$$

From this expression, the diffusion coefficient $\mathrm{D}$ can be determined by plotting $\mathrm{S}_{t} / \mathrm{S}_{\text {sat }}$ as a function of $\mathrm{t}^{1 / 2} / \mathrm{L}$ and fitting a linear relation. Note the presence of $\mathrm{S}_{\text {sat }}$ in equation (2), indicating this expression requires the polymer thin film to reach saturation in order to be valid. In the current study, none of the polymer thin films reached saturation upon 5 min of TMA exposure.

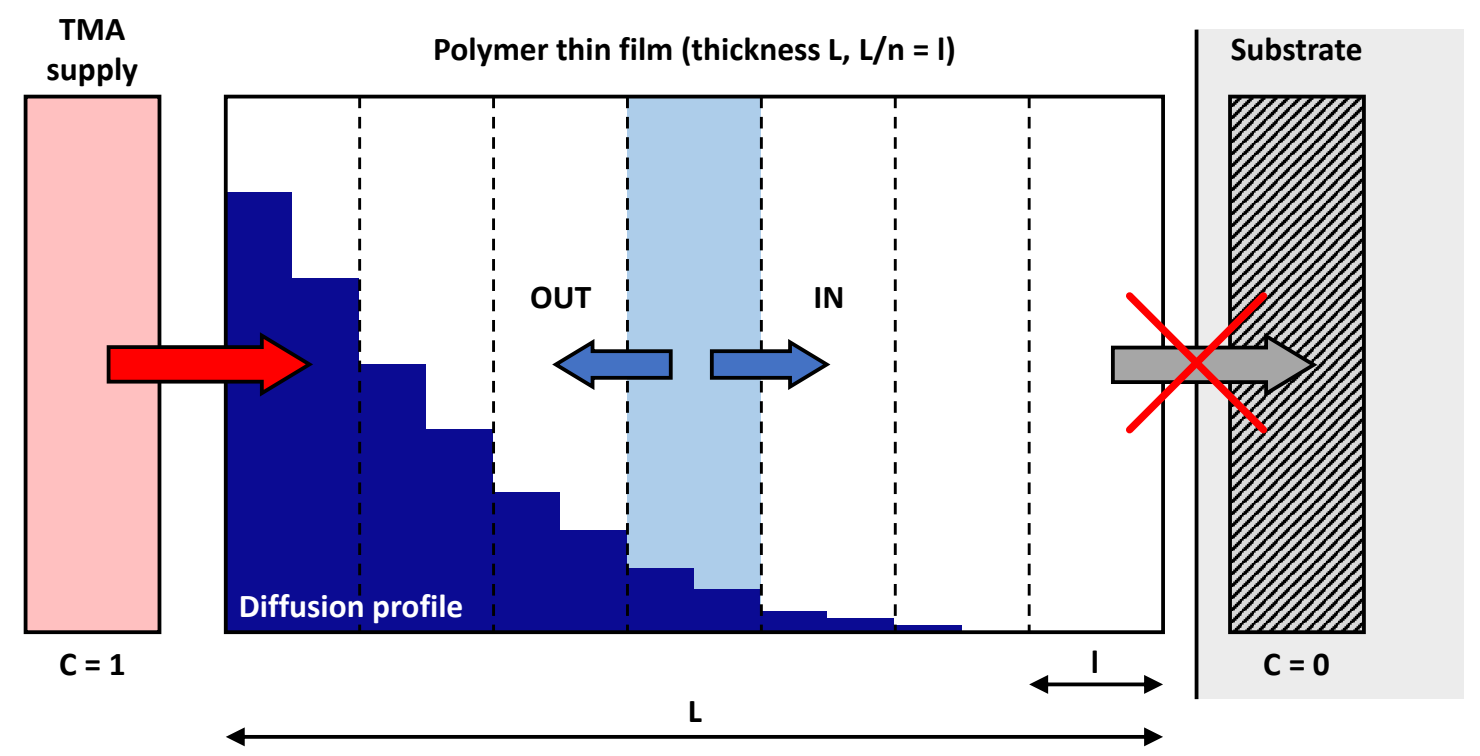

Figure S1: Illustration of the numerical model used to describe the infiltration process of TMA into the polymer thin films. 
As an alternative, TMA diffusion coefficients for PS, PMMA and PET-G were determined through a numerical implementation of the infiltration process, governed by Fickian kinetics. A schematic representation of the numerical model is shown in Fig. S1. The polymer thin film is divided in $n+2$ intervals of length $\mathrm{l}=\mathrm{L} / \mathrm{n}$. The supply of TMA is incorporated as a first interval with a constant concentration equal to 1 , corresponding to a non-finite supply of TMA during the exposure time. During each timestep, $\mathrm{t}_{\text {step }}$, the TMA concentration inside the individual intervals is allowed to change under the influence of the concentration gradient over the entire polymer thin film, induced by the supply of TMA. Following Fick's first law of diffusion, an iterative expression was found describing the concentration change within one interval i during a single timestep:

$$
C_{i}^{*}=C_{i}+\left(\frac{D t_{\text {step }}}{l^{2}}\right)\left(C_{i-1}-2 C_{i}+C_{i+1}\right)
$$

No diffusion is allowed to happen from the polymer thin films towards the substrate, which is taken into account by adjusting the concentration of the final interval, $i=n+2$, to be equal to the concentration of interval $\mathrm{i}=\mathrm{n}+1$, i.e. no diffusion occurs between the polymer thin film and the substrate due to the absence of a concentration gradient. Diffusion of TMA out of the polymer thin film is obtained by setting the concentration of the first interval, the TMA supply, to zero causing a reverse concentration gradient. The total concentration within the polymer thin film as a function of time can be obtained through integration over all intervals related to the polymer thin film $(\mathrm{i}=2,3, \ldots, \mathrm{n}+1)$. Similar to the approach discussed above, it is assumed that the polymer swelling $\mathrm{S}_{t}$ is linearly dependent on the concentration of infiltrated TMA $\mathrm{C}_{t}$, resulting in the following expression:

$$
S_{t} \approx L C_{t}=L \int C_{x, t} d x
$$

in which $\mathrm{L}$ is again the initial thickness of the polymer thin film. The resulting polymer thickness, taking into account the polymer swelling, is then: $\mathrm{L}+\mathrm{S}_{t}$.

The TMA diffusion coefficient for PS, PMMA and PET-G can now be determined by inserting the correct values for $\mathrm{t}_{\text {step }}$ and $\mathrm{l}=\mathrm{L} / \mathrm{n}$ and allowing $\mathrm{D}$ to vary. In this way, an order of magnitude estimate for $\mathrm{D}$ is obtained after comparison between the experimental data (i.e. in situ SE) and the simulated data (Fig. S2). Here $\mathrm{t}_{\text {step }}$ is defined as $\mathrm{T}=5 \mathrm{~min}=\tau \cdot \mathrm{t}_{\text {step }}$, in which $\tau$ is the total number of steps and $\mathrm{T}$ is the total exposure time equal to $5 \mathrm{~min}$ in agreement with the in situ SE data.

In Fig. S2, it is observed that the polymer swelling measured using in situ SE deviates from the simulated polymer swelling indicating a variable diffusion coefficient, i.e. the diffusion of TMA into the polymer thin film appears to slow down for extended exposure times. One reason for this retardation might be that the infiltrated TMA molecules change the local environment within the polymer thin film and thereby slow down the infiltration of the following TMA molecules into the polymer thin film. In addition, the model used to fit the in situ SE data and the basic numerical model used to simulate the polymer swelling cannot fully describe the interaction between TMA and the polymer thin films and require further optimization. 

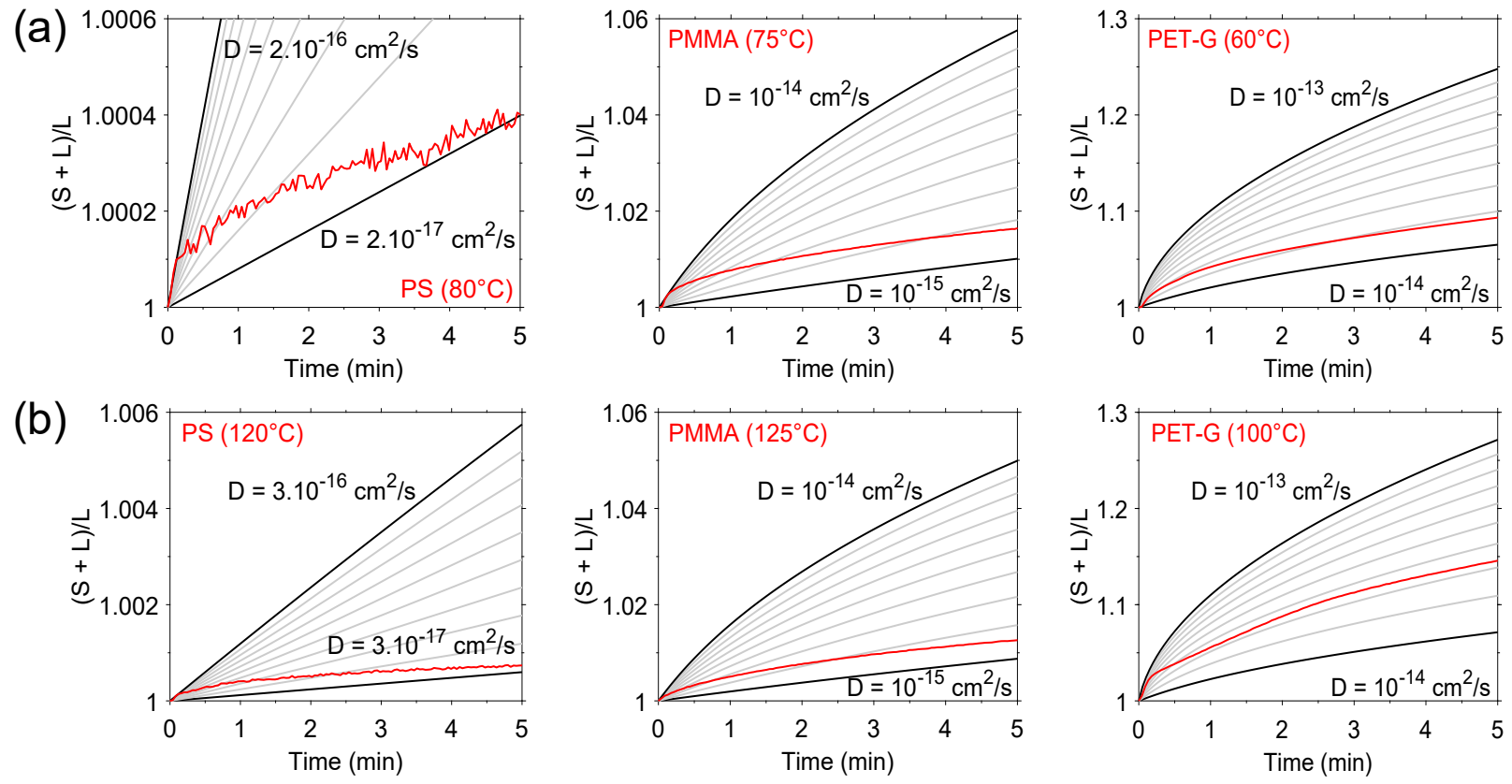

Figure S2: Determination of the TMA diffusion coefficient in PS, PMMA and PET-G thin films at temperatures below (PS: $80^{\circ} \mathrm{C}$, PMMA: $75^{\circ} \mathrm{C}$, PET-G: $60^{\circ} \mathrm{C}$ ) and above (PS: $120^{\circ} \mathrm{C}$, PMMA: $125^{\circ} \mathrm{C}$, PET-G: $100^{\circ} \mathrm{C}$ ) the glass transition temperature (PS: $100^{\circ} \mathrm{C}$, PMMA: $105^{\circ} \mathrm{C}, \mathrm{PET}-\mathrm{G}: 80^{\circ} \mathrm{C}$ ). 


\section{In situ FTIR spectra for PS}

Using in situ FTIR difference spectra, the reaction between TMA and the PMMA and PET-G thin films was investigated. The positive and negative features that appeared after TMA exposure indicate the addition and consumption of surface species and enabled the construction of a reaction mechanism. The in situ FTIR difference spectra for PS below and above the glass transition temperature $\left(100^{\circ} \mathrm{C}\right)$ are shown in Fig. S3. At both temperatures, weak positive features are observed after the TMA exposure at 2936-2937 $\mathrm{cm}^{-1}$, $1197-1200 \mathrm{~cm}^{-1}$ and $693.3 \mathrm{~cm}^{-1}$ indicating possible TMA surface adsorption, in agreement with TMA being largely unreactive towards the PS thin film due to the absence of functional groups.
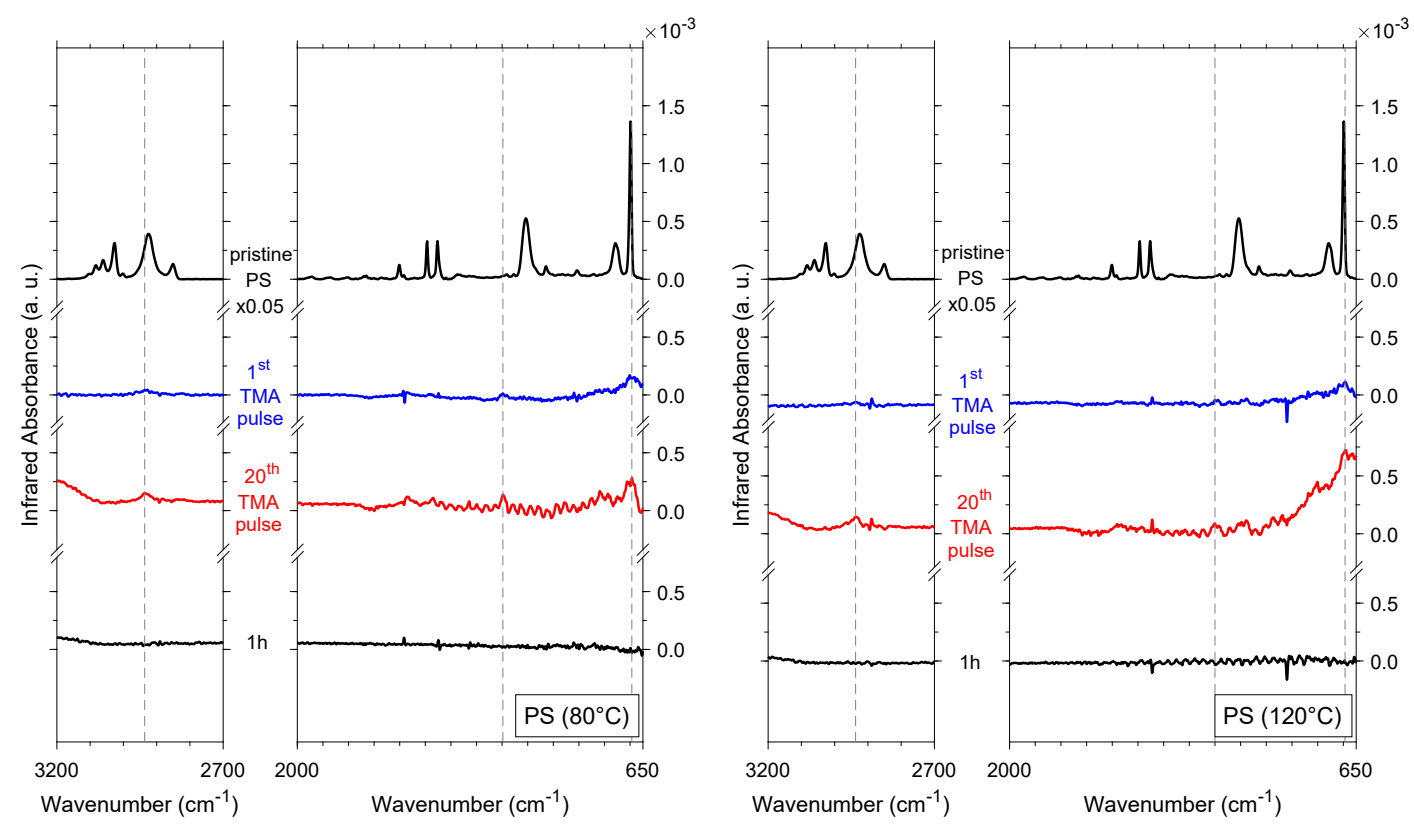

Figure S3: In situ FTIR difference spectra for the PS thin film below and above glass transition temperature showing the effect of TMA exposure. The spectra corresponding to the $1^{\text {st }}$ TMA pulse and the $20^{\text {th }}$ TMA pulse are plotted as the difference to the pristine FTIR spectrum, the spectrum obtained after approximately $1 \mathrm{~h}$ waiting period is plotted as the difference to the spectrum of the $20^{t h}$ TMA pulse, corresponding to the end of the TMA exposure.

\subsection{Note on the in situ FTIR difference spectra}

During the collection of the in situ FTIR data the ALD reactor chamber and the FTIR measuring instrument have likely suffered from contamination by vacuum grease (possibly due to overheating). This becomes apparent from the "artificial" peaks located at $2915 \mathrm{~cm}^{-1}$ and $2847 \mathrm{~cm}^{-1}$ which are clearly present in the FTIR difference spectra obtained after the $4 \mathrm{~h}$ waiting period following the final TMA pulse (in particular Fig. 3(a)). This was further confirmed by the fact that these peaks were already present at the beginning of the experiment and slowly increased in magnitude over time. Therefore the allocation of the different peaks/bands in the region from $2600 \mathrm{~cm}^{-1}$ to $3100 \mathrm{~cm}^{-1}$ is not so straightforward and prone to errors. The presence of these "artificial" peaks however does not affect the conclusions made in this study regarding the exact mechanism and reversibility of the reaction between TMA and the polymer thin films. No overlap between the peaks arising from the contamination and the peaks from the polymer related to the chemical groups contributing to the reaction with TMA was observed. Due to excessive contamination and large oscillations in the FTIR difference spectrum corresponding to the $4 \mathrm{~h}$ waiting period, the FTIR difference spectrum is shown for a waiting period of approximately $1 \mathrm{~h}$ in Fig. 3 (PMMA $125^{\circ} \mathrm{C}$ ) and Fig. S3 (PS $80^{\circ} \mathrm{C}$, PS $120^{\circ} \mathrm{C}$ ). No differences are observed between the spectra corresponding to a $1 \mathrm{~h}$ and a $4 \mathrm{~h}$ waiting period, other than the magnitude of the features. 


\section{$3 \quad$ FTIR peak allocations}

Table S1: Allocation of the infrared absorbance peaks/bands for PS, PMMA and PET-G.

\begin{tabular}{|c|c|c|}
\hline polymer & wavenumber range $\left(\mathrm{cm}^{-1}\right)$ & peaks/bands \\
\hline PS $[4,5]$ & $\begin{array}{l}3082,3061,3026 \\
2924 \\
2851 \\
1944,1871,1801,1740,1670 \\
1601,1584 \\
1493,1452 \\
1028 \\
758,698\end{array}$ & $\begin{array}{l}\text { aromatic } \mathrm{C}-\mathrm{H} \text { stretching } \\
\text { asymmetric stretching of methylene, }-\mathrm{CH}_{2} \\
\text { symmetric stretching of methylene, }-\mathrm{CH}_{2} \\
\text { overtones and combination bands } \\
\text { (mono-substituted aromatic ring) } \\
\text { aromatic } \mathrm{C}-\mathrm{C} / \mathrm{C}=\mathrm{C} \text { stretching } \\
\text { (in-plane ring breathing modes) } \\
\text { aromatic } \mathrm{C}-\mathrm{C} / \mathrm{C}=\mathrm{C} \text { stretching } \\
\text { (ring breathing/-CH} 2 \text { deformation vibration) } \\
\text { in-plane } \mathrm{C}-\mathrm{H} \text { bending of the phenyl ring } \\
\text { out-of-plane } \mathrm{C}-\mathrm{H} \text { bending of the phenyl ring }\end{array}$ \\
\hline PMMA [6-12] & $\begin{array}{l}2997-2953,2843 \\
1732 \\
1485,1450 \\
1389 \\
1267,1192,1150 \\
1242 \\
1067,992 \\
966 \\
912,841 \\
752\end{array}$ & $\begin{array}{l}\mathrm{C}-\mathrm{H} \text { stretching of }-\mathrm{CH}_{3} \text { and }-\mathrm{CH}_{2} \\
\mathrm{C}=\mathrm{O} \text { stretching } \\
\mathrm{C}-\mathrm{H} \text { bending of }-\mathrm{CH}_{2} \text { and }-\mathrm{CH}_{3} \\
\alpha-\mathrm{CH}_{3} \text { bending ( } \mathrm{symmetric} \text { ) } \\
\mathrm{C}-\mathrm{O}-\mathrm{R} \text { stretching, }-\mathrm{CH}_{3}-\mathrm{O} \text { stretching } \\
-\mathrm{CH}_{2} \text { twisting, } \mathrm{C}-\mathrm{C}-\mathrm{O} \text { stretch } \\
\mathrm{C}-\mathrm{C} \text { stretching, O- } \mathrm{CH}_{3} \text { rocking } \\
\alpha-\mathrm{CH}_{3} \text { rocking/O-CH} \text { stretching } \\
-\mathrm{CH}_{3},-\mathrm{CH}_{2} \text { rocking } \\
\alpha-\mathrm{CH}_{3} \text { vibration/C-C stretching }\end{array}$ \\
\hline PET-G $[12-16]$ & $\begin{array}{l}2941,2858 \\
1722 \\
1614,1580,1504 \\
1452 \\
1410,1339 \\
1265 \\
1120 \\
1100 \\
1018 \\
958 \\
875,729\end{array}$ & $\begin{array}{l}\text { asymmetric/symmetric aliphatic } \mathrm{C}-\mathrm{H} \text { stretching } \\
\mathrm{C}=\mathrm{O} \text { stretching } \\
\mathrm{C}-\mathrm{C} \text { stretching vibrations in the benzene rings } \\
\text { aromatic } \mathrm{C}-\mathrm{C} / \mathrm{C}=\mathrm{C} \text { stretching, }-\mathrm{CH}_{2} \text { - bending } \\
\text { - } \mathrm{CH}_{2} \text { - deformation/bending and wagging } \\
\text { vibrational modes of the ethylene glycol segment } \\
\mathrm{C}-\mathrm{O}-\mathrm{C} \text { stretching/terephthalate group } \\
\text { terephthalate group } \\
\mathrm{C}-\mathrm{O}-\mathrm{C} \text { stretching/vibrations ester } \mathrm{C}-\mathrm{O} \text { bond } \\
\mathrm{C}-\mathrm{H} \text { in-plane vibrations } \\
\mathrm{C}-\mathrm{H} \text { stretching of cyclohexylene ring } \\
\mathrm{C}-\mathrm{H} \text { out-of-plane deformation of two carbonyl } \\
\text { substituents on the aromatic ring }\end{array}$ \\
\hline
\end{tabular}


Table S2: Overview of the changes in the FTIR spectrum of PS, PMMA and PET-G after TMA exposure. Positive features are denoted by an upward arrow and negative features by a downward arrow.

\begin{tabular}{|c|c|c|c|c|c|}
\hline \multicolumn{2}{|c|}{ PMMA $\left(\mathrm{cm}^{-1}\right)$} & \multicolumn{2}{|c|}{ PET-G $\left(\mathrm{cm}^{-1}\right)$} & \multirow[b]{2}{*}{$\uparrow / \downarrow$} & \multirow[b]{2}{*}{ peaks/bands } \\
\hline $75^{\circ} \mathrm{C}$ & $125^{\circ} \mathrm{C}$ & $60^{\circ} \mathrm{C}$ & $100^{\circ} \mathrm{C}$ & & \\
\hline 2938 & 2923 & 2926 & 2939 & $\uparrow$ & $\mathrm{C}-\mathrm{H}$ stretching of $\mathrm{Al}-\mathrm{CH}_{3}$ \\
\hline 1 & 1 & / & 1738 & $\uparrow$ & possible $\mathrm{C}=\mathrm{O}$ shift \\
\hline $1730^{a}$ & $1727^{a}$ & $1717^{c}$ & $1717^{c}$ & $\downarrow$ & $\mathrm{C}=\mathrm{O}$ stretching $(\mathrm{a}, \mathrm{c}=$ amorphous, crystalline $)$ \\
\hline 1670 & 1668 & 1660 & l & $\uparrow$ & TMA physisorption, $\mathrm{C}=\mathrm{O}$ red shift \\
\hline 1302 & 1297 & 1331 & / & $\uparrow$ & TMA physisorption, $\mathrm{C}=\mathrm{O}$ blue shift \\
\hline 1270 & 1268 & 1253 & 1250 & $\downarrow$ & $\mathrm{C}-\mathrm{O}$ stretching \\
\hline 1204 & 1205 & 1195 & 1195 & $\uparrow$ & $\mathrm{Al}-\mathrm{CH}_{3}$ stretching and deformation modes \\
\hline 1145 & 1145 & / & l & $\downarrow$ & $\mathrm{C}-\mathrm{O}$ stretching \\
\hline / & / & 1119 & 1119 & $\downarrow$ & terephthalate group \\
\hline / & / & 1100 & 1098 & $\downarrow$ & $\mathrm{C}-\mathrm{O}-\mathrm{C}$ stretching/vibrations ester $\mathrm{C}-\mathrm{O}$ bond \\
\hline / & / & 727 & 727 & $\downarrow$ & C-H out-of-plane deformation \\
\hline 705 & 700 & 698 & 695 & $\uparrow$ & $\mathrm{C}-\mathrm{H}$ rocking of $\mathrm{Al}-\mathrm{CH}_{3}$ \\
\hline
\end{tabular}




\section{In vacuo XPS spectra for the $\mathrm{C}_{1 s}, \mathrm{O}_{1 s}$ and $\mathrm{Al}_{2 p}$ elemental peaks}

The XPS data was analyzed using CasaXPS (Casa Software Ltd.). The XPS peaks were deconvoluted into separate components relating to the specific chemical states or bond types of the atoms in the polymer structures. The $\mathrm{C}_{1 s}$ peak for PS consists of two components at a 3:1 ratio corresponding to aromatic carbon $(284.70 \mathrm{eV})$ and aliphatic carbon $(284.99 \mathrm{eV})$ respectively, separated by $\approx 0.29 \mathrm{eV}$, which is close to the reported $0.30 \mathrm{eV}$ [17]. Additionally, a shake-up satellite is visible at approximately $291.0 \mathrm{eV}$. For PMMA, four individual components were used in the peak model: $\mathrm{C}-\mathrm{H}(284.8 \mathrm{eV}), \mathrm{C}-\mathrm{C}(285.3 \mathrm{eV}-285.6 \mathrm{eV}), \mathrm{C}-\mathrm{O}$ $(286.9 \mathrm{eV})$ and $\mathrm{C}=\mathrm{O}(289.0 \mathrm{eV}-289.2 \mathrm{eV})(2: 1: 1: 1)$. The $\mathrm{C}_{1 s}$ peak for PET-G was deconvoluted into three components, C-C/C-H, C-O and $\mathrm{C}=\mathrm{O}$ at $284.8 \mathrm{eV}, 286.5 \mathrm{eV}$ and $288.8 \mathrm{eV}$ respectively (9:2:2). The ratios mentioned here correspond to the expected ratios based on the polymer structures [17]. The measured ratios are (3.4:1) for PS, (5.6:1.9:2.1:1) for PMMA and (8.2:1:1.3) for PET-G. As can be seen for all polymers, the measured ratios of the $\mathrm{C}_{1 s}$ components deviate from the expected values due to an increased contribution from the $\mathrm{C}-\mathrm{C} / \mathrm{C}-\mathrm{H}$ component located at $284.8 \mathrm{eV}$. Presumably this results from carbon contamination at the surface of the polymer thin films.

For PMMA, two peak components can be identified in the $\mathrm{O}_{1 s}$ peak associated with $\mathrm{O}-\mathrm{C}(534.2 \mathrm{eV})$ and $\mathrm{O}=\mathrm{C}(532.7 \mathrm{eV})$ at a $1: 1$ ratio. Similarly, the $\mathrm{O}_{1 s}$ peak for PET-G consists of an O-C component at 533.7 $\mathrm{eV}$ and an $\mathrm{O}=\mathrm{C}$ component at $532.1 \mathrm{eV}(1: 1)$.

A clear $\mathrm{Al}_{2 p}$ peak is observed for the PMMA and PET-G thin films after the TMA exposure originating from reacted or shallowly infiltrated TMA. The $\mathrm{Al}_{2 p}$ peak remains absent in the case of PS, being unreactive towards the TMA molecules due to the lack of functional groups.

(a)
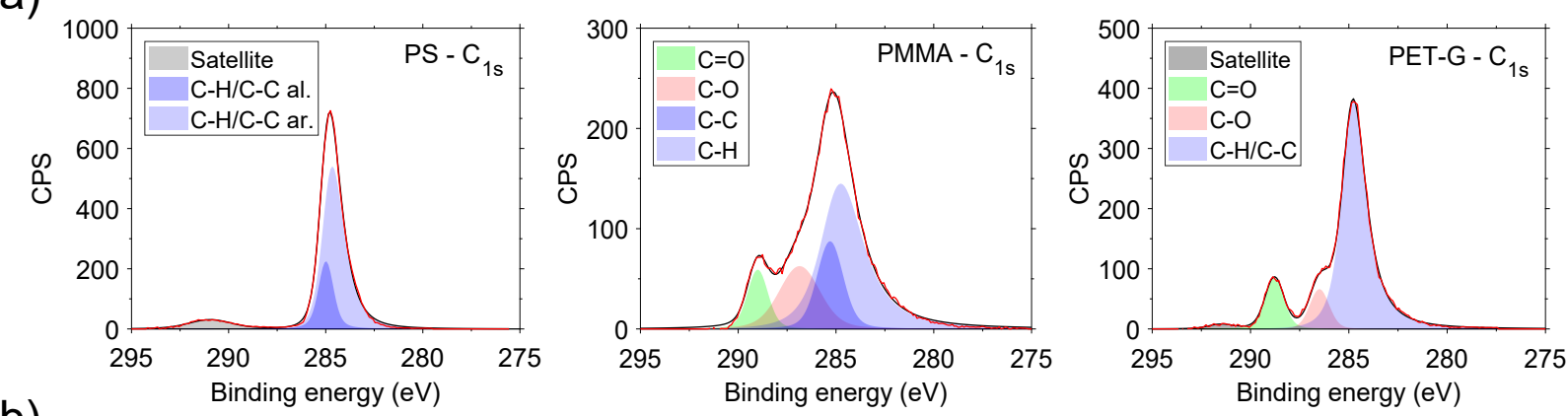

(b)
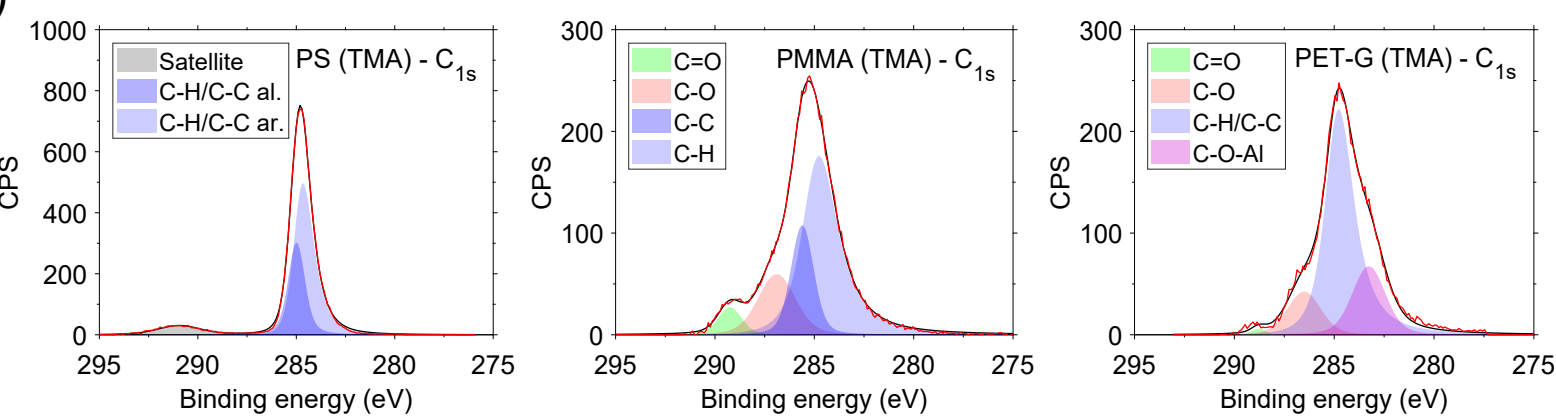

Figure S4: XPS peak models for the deconvolution of the $\mathrm{C}_{1 s}$ elemental peak in PS, PMMA and PET-G thin films before (a) and after (b) TMA exposure. 

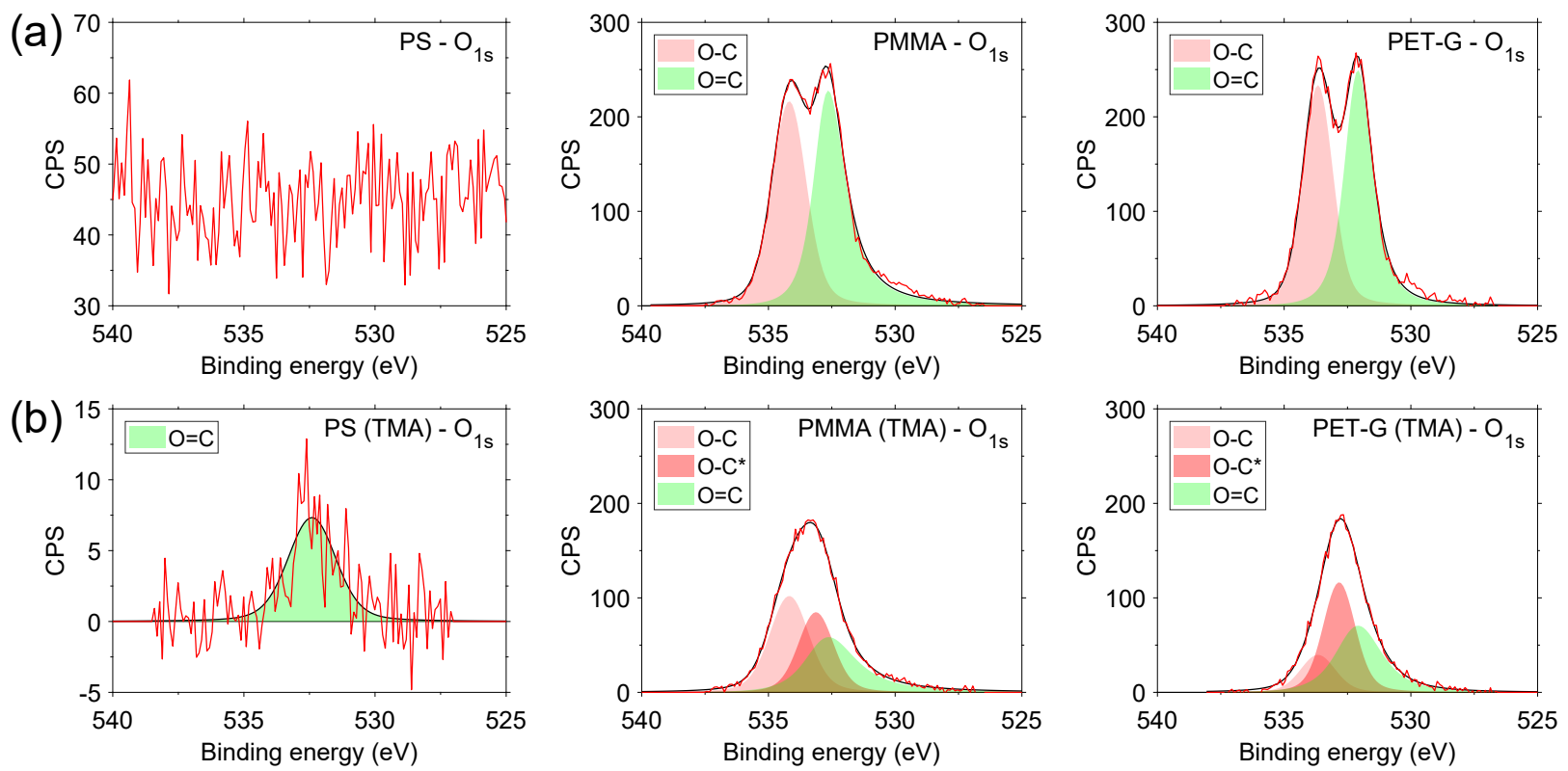

Figure S5: XPS peak models for the deconvolution of the $\mathrm{O}_{1 s}$ elemental peak in PS, PMMA and PET-G thin films before (a) and after (b) TMA exposure.

(a)

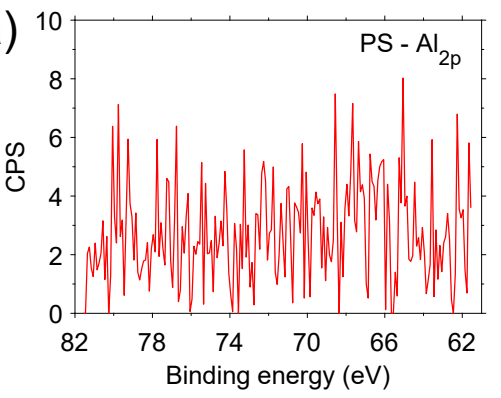

(b)

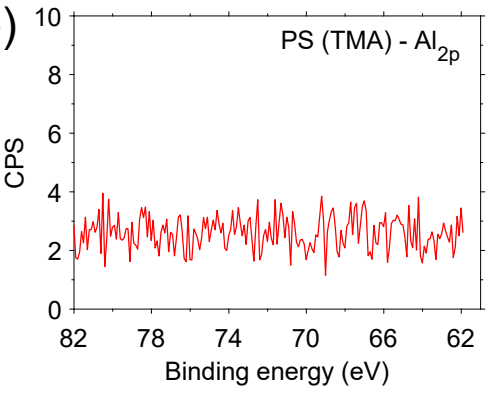

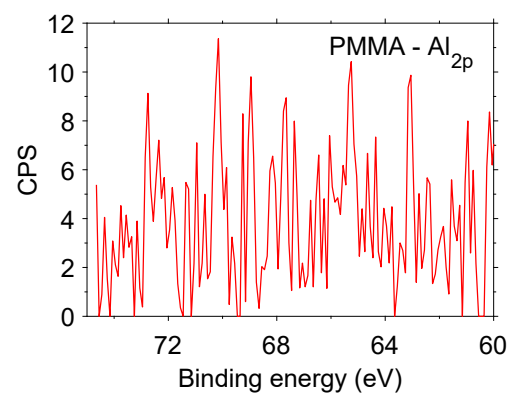


Figure S6: XPS peak models for the deconvolution of the $\mathrm{Al}_{2 p}$ elemental peak in PS, PMMA and PET-G thin films before (a) and after (b) TMA exposure. 


\section{Determination of the linear growth delay}

During the $\mathrm{Al}_{2} \mathrm{O}_{3}$-ALD process (TMA $+\mathrm{H}_{2} \mathrm{O}$ ) on PS, PMMA, PET-G thin films a linear growth delay was observed using in situ SE, defined as the number of ALD cycles before linear ALD growth is obtained. The linear growth delay was determined by the intercept with the $\mathrm{x}$-axis $(\mathrm{y}=0)$ after fitting the linear regime of the ALD growth curve. For PET-G, the intercept was determined using $\mathrm{y}=\alpha=$ constant, with $\alpha$ the initial thickness increase due to significant infiltration of TMA into the PET-G thin film. Figs. S7-S9 demonstrate the determination of the linear growth delay for the PS, PMMA and PET-G thin films at temperatures below and above the glass transition temperature of the polymers. Fig. S10 shows the initial increase in thickness of the PET-G thin film due to TMA infiltration as a function of temperature. A similar trend to the one for the linear growth delay is observed with saturation of the thickness increase for temperatures above the glass transition temperature.
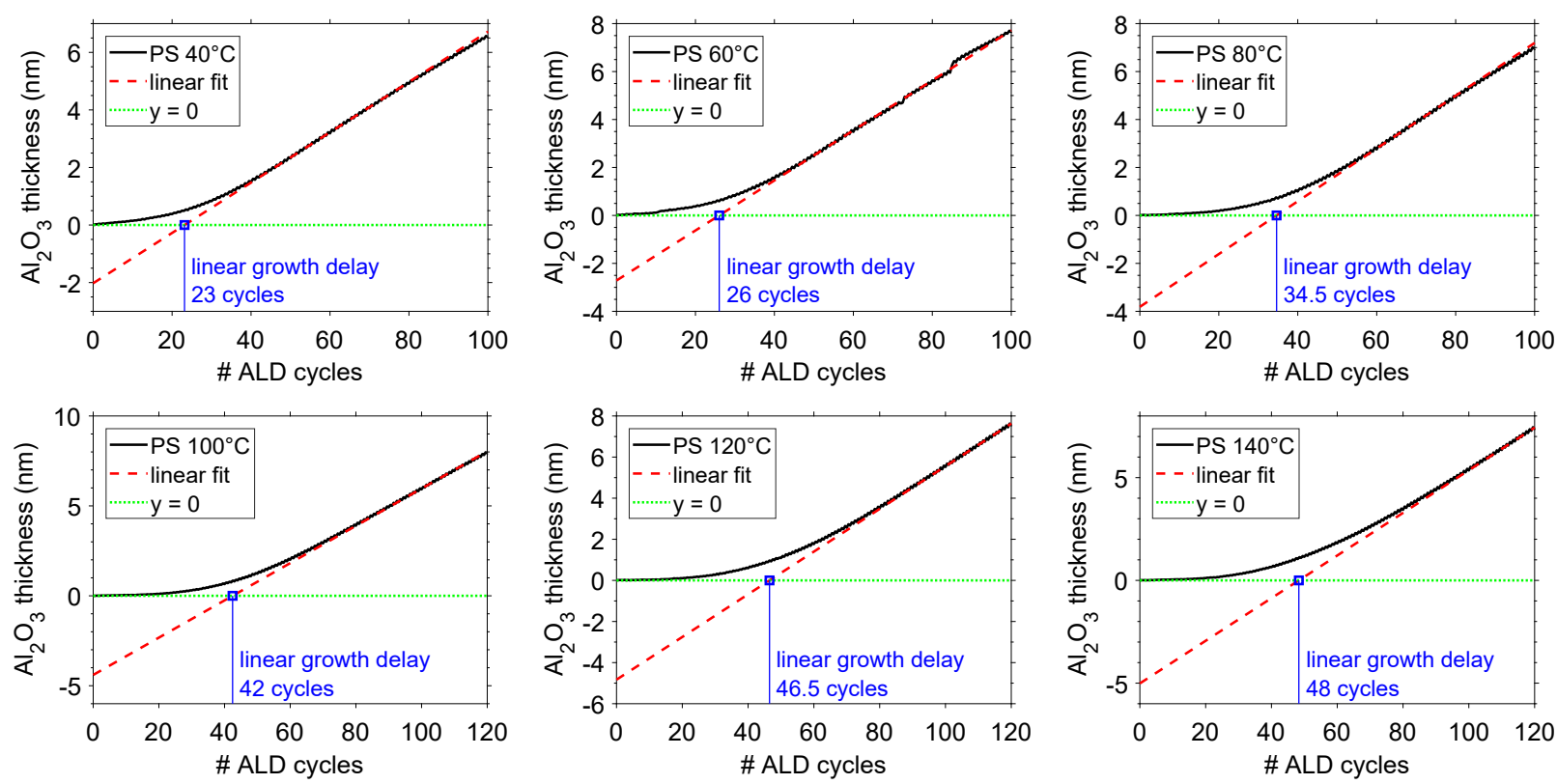

Figure S7: Determination of the linear growth delay from in situ SE data for $\mathrm{Al}_{2} \mathrm{O}_{3}-\mathrm{ALD}$ on PS thin films at different temperatures $\left(40^{\circ} \mathrm{C}, 60^{\circ} \mathrm{C}, 80^{\circ} \mathrm{C}, \mathrm{Tg}=100^{\circ} \mathrm{C}, 120^{\circ} \mathrm{C}\right.$ and $\left.140^{\circ} \mathrm{C}\right)$. 

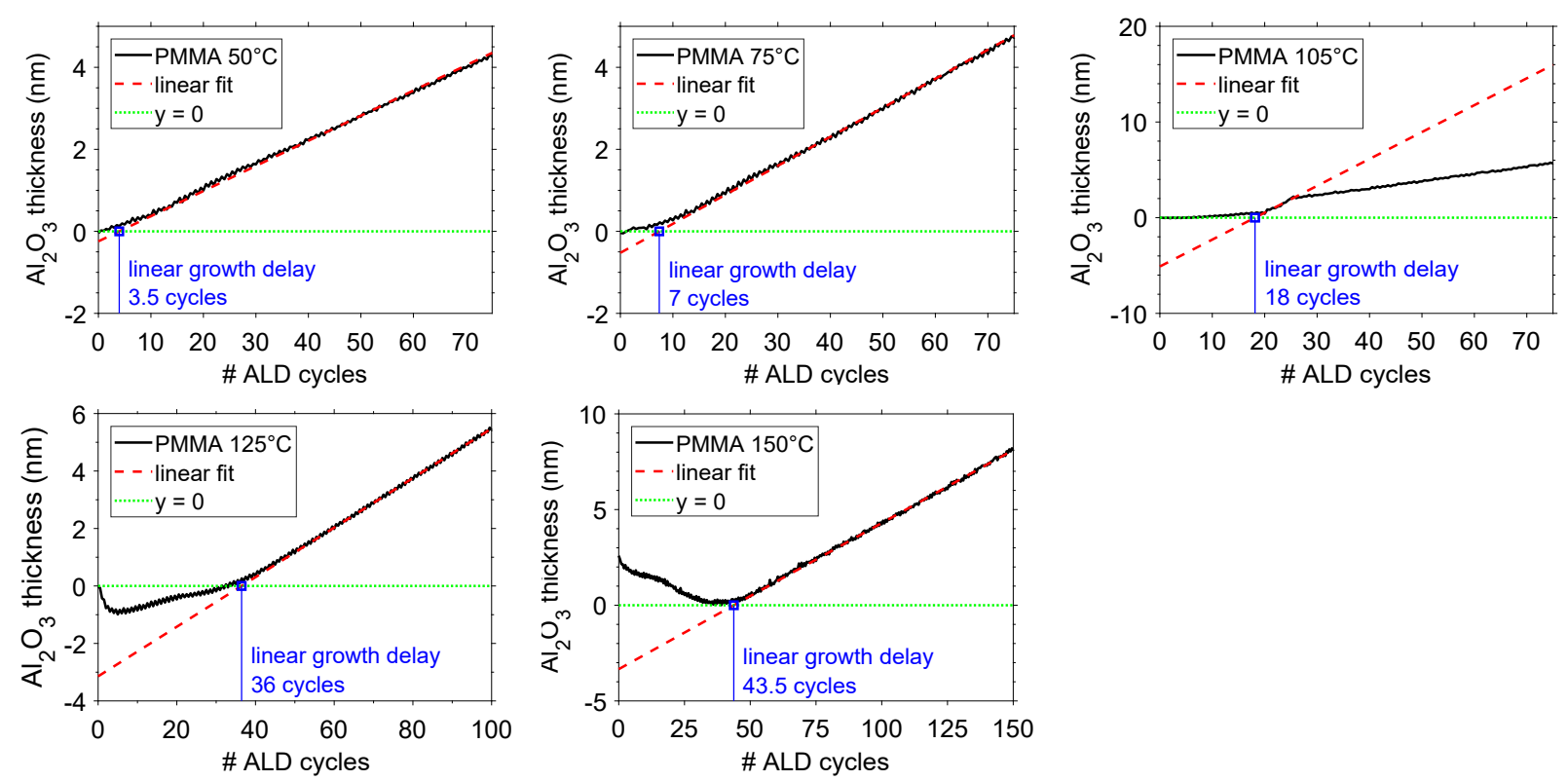

Figure S8: Determination of the linear growth delay from in situ SE data for $\mathrm{Al}_{2} \mathrm{O}_{3}-\mathrm{ALD}$ on PMMA thin films at different temperatures $\left(50^{\circ} \mathrm{C}, 75^{\circ} \mathrm{C}, \mathrm{Tg}=105^{\circ} \mathrm{C}, 125^{\circ} \mathrm{C}\right.$ and $\left.150^{\circ} \mathrm{C}\right)$. The in situ $\mathrm{SE}$ data corresponding to $150^{\circ} \mathrm{C}$ was shifted in the positive $\mathrm{y}$-direction by $2.61 \mathrm{~nm}$ to determine the linear growth delay, as a result of the decrease in thickness at the start of the deposition.
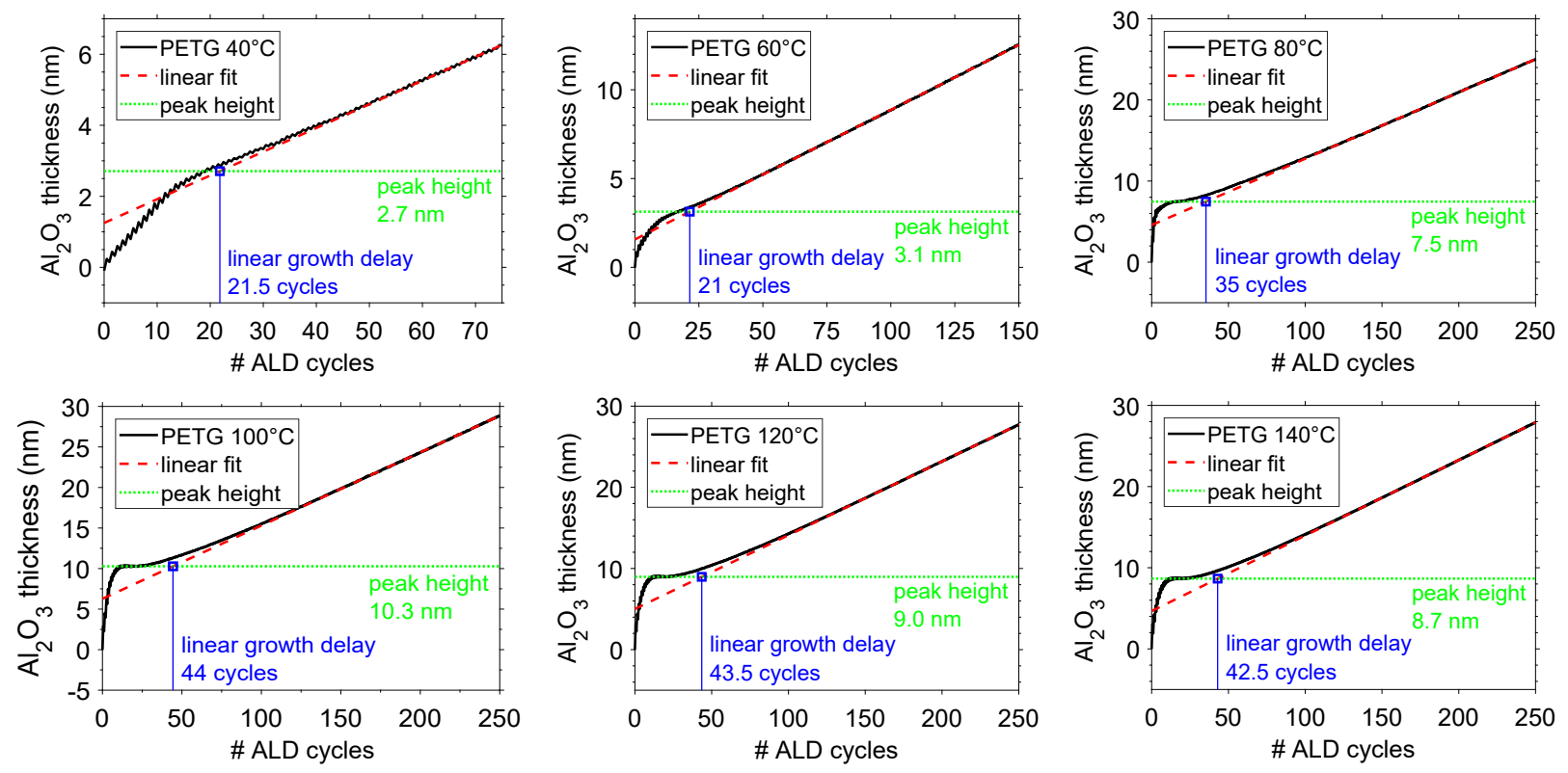

Figure S9: Determination of the linear growth delay from in situ SE data for $\mathrm{Al}_{2} \mathrm{O}_{3}-\mathrm{ALD}$ on PET-G thin films at different temperatures $\left(40^{\circ} \mathrm{C}, 60^{\circ} \mathrm{C}, \mathrm{Tg}=80^{\circ} \mathrm{C}, 100^{\circ} \mathrm{C}, 120^{\circ} \mathrm{C}\right.$ and $\left.140^{\circ} \mathrm{C}\right)$. 


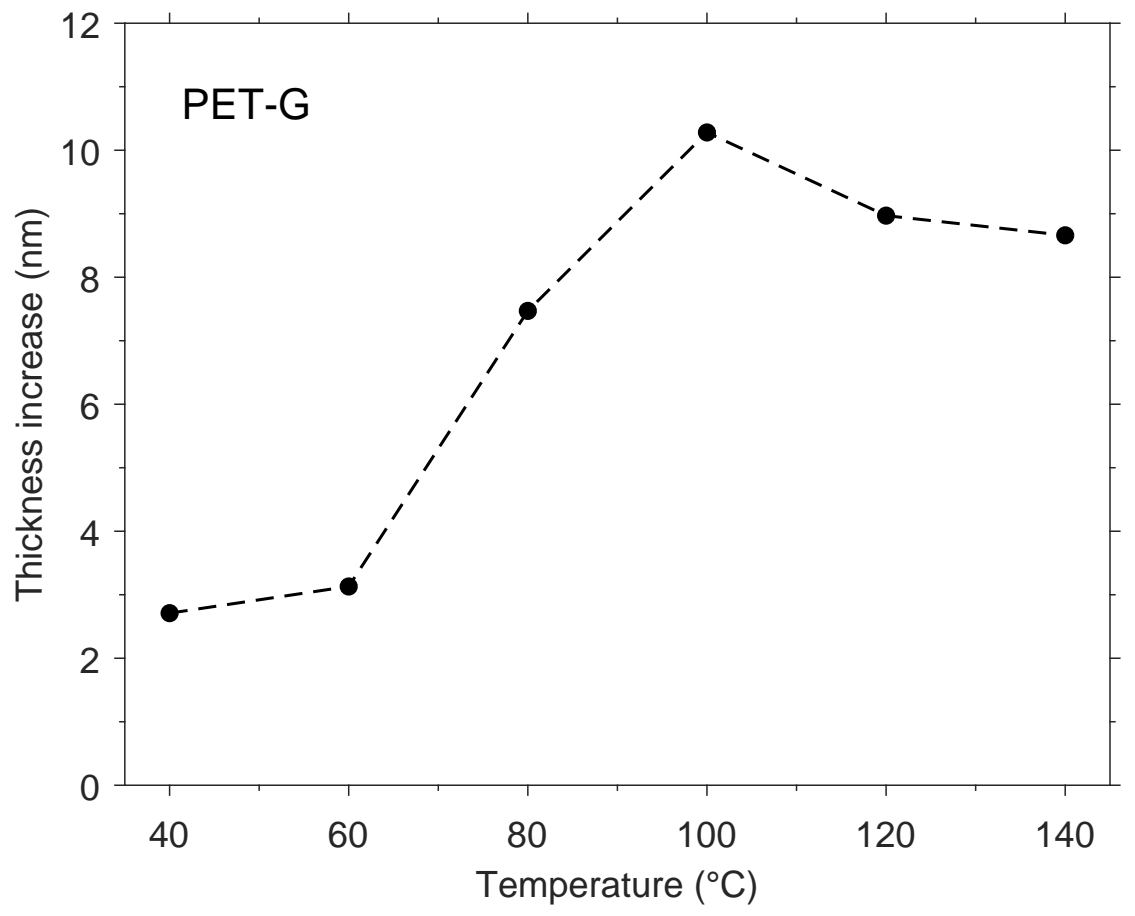

Figure S10: Initial thickness increase as a function of temperature during exposure of the PET-G thin film to TMA. 


\section{In situ SE: TMA infiltration and closed layer formation during ALD for temperatures below $\mathrm{Tg}$}

The polymer swelling and closed layer formation during ALD at temperatures below and above the glass transition temperature of the polymers (PS: $100^{\circ} \mathrm{C}$, PMMA: $105^{\circ} \mathrm{C}, \mathrm{PET}-\mathrm{G}$ : $80^{\circ} \mathrm{C}$ ) was investigated. The figures below correspond to temperatures below the glass transition temperature (PS: $80^{\circ} \mathrm{C}, \mathrm{PMMA}: 75^{\circ} \mathrm{C}$ and PET-G: $60^{\circ} \mathrm{C}$ ). No striking differences were observed in the TMA infiltration behaviour for the PS and PMMA thin films compared to Fig. 6 in the manuscript, showing the situation for temperatures above the glass transition temperature. For PET-G a significant reduction in the polymer swelling at lower temperatures indicates a huge decrease in the extent of TMA infiltration into the polymer thin film. The moment at which a closed ALD layer is formed through the interaction between TMA and $\mathrm{H}_{2} \mathrm{O}$ appears to not be strongly influenced by the decrease in temperature.
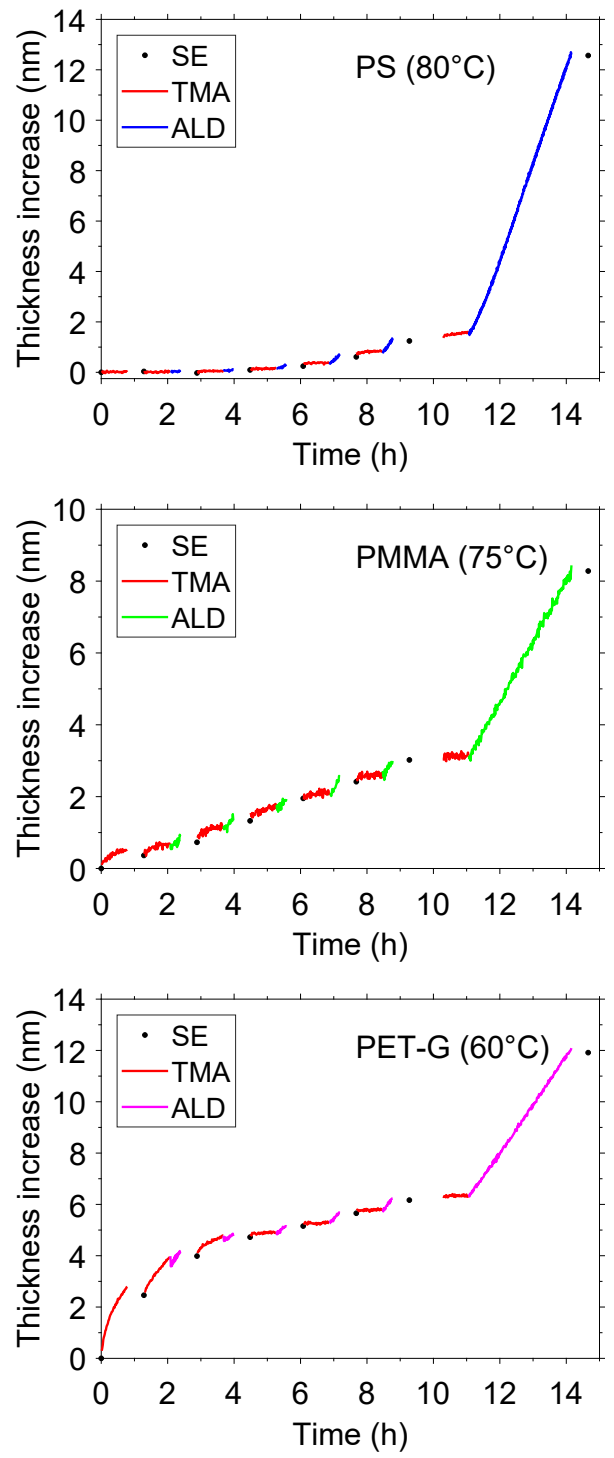

Figure S11: In situ SE data showing TMA infiltration and closed layer formation for the PS, PMMA and PET-G thin films at temperatures (PS: $80^{\circ} \mathrm{C}$, PMMA: $75^{\circ} \mathrm{C}$ and PET-G: $60^{\circ} \mathrm{C}$ ) below the glass transition temperature (PS: $100^{\circ} \mathrm{C}$, PMMA: $\left.105^{\circ} \mathrm{C}, \mathrm{PET}-\mathrm{G}: 80^{\circ} \mathrm{C}\right)$. 


\section{References}

[1] Cianci, E.; Nazzari, D.; Seguini, G.; Perego, M. Trimethylaluminum Diffusion in PMMA Thin Films during Sequential Infiltration Synthesis: In Situ Dynamic Spectroscopic Ellipsometric Investigation. Advanced Materials Interfaces 2018, 5 (20), 1801016, DOI: https://doi.org/10.1002/admi.201801016.

[2] Caligiore, F. E.; Nazzari, D.; Cianci, E.; Sparnacci, K.; Laus, M.; Perego, M.; Seguini, G. Effect of the Density of Reactive Sites in $\mathrm{P}$ (S-r-MMA) Film during $\mathrm{Al}_{2} \mathrm{O}_{3}$ Growth by Sequential Infiltration Synthesis. Advanced Materials Interfaces 2019, 6 (12), 1900503, DOI: https://doi.org/10.1002/admi.201900503.

[3] Crank, J. The mathematics of diffusion / by J. Crank, Clarendon Press: Oxford [England], 1975.

[4] Olmos, D.; Martín, E. V.; González-Benito, J. New molecular-scale information on polystyrene dynamics in $\mathrm{PS}$ and $\mathrm{PS}-\mathrm{BaTiO}_{3}$ composites from FTIR spectroscopy. Physical Chemistry Chemical Physics 2014, 16 (44), 24339-24349, DOI: 10.1039/C4CP03516J.

[5] Fang, J.; Xuan, Y.; Li, Q. Preparation of polystyrene spheres in different particle sizes and assembly of the PS colloidal crystals. Science China-technological Sciences - SCI CHINA-TECHNOL SCI 2010, 53, 3088-3093, DOI: 10.1007/s11431-010-4110-5.

[6] Parsons, G. N.; Atanasov, S. E.; Dandley, E. C.; Devine, C. K.; Gong, B.; Jur, J. S.; Lee, K.; Oldham, C. J.; Peng, Q.; Spagnola, J. C.; Williams, P. S. Mechanisms and reactions during atomic layer deposition on polymers. Coordination Chemistry Reviews 2013, 257 (23), 3323-3331, DOI: https://doi.org/10.1016/j.ccr.2013.07.001.

[7] Biswas, M.; Libera, J. A.; Darling, S. B.; Elam, J. W. New Insight into the Mechanism of Sequential Infiltration Synthesis from Infrared Spectroscopy. Chemistry of Materials 2014, 26 (21), 6135-6141, DOI: 10.1021/cm502427q.

[8] Duan, G.; Zhang, C.; Li, A.; Yang, X.; Lu, L.; Wang, $\mathrm{X}$. Preparation and Characterization of Mesoporous Zirconia Made by Using a Poly (methyl methacrylate) Template. Nanoscale Research Letters 2008, 3 (3), 118, DOI: 10.1007/s11671-008-9123-7.

[9] Dandley, E. C.; Needham, C. D.; Williams, P. S.; Brozena, A. H.; Oldham, C. J.; Parsons, G. N. Temperature-dependent reaction between trimethylaluminum and poly(methyl methacrylate) during sequential vapor infiltration: experimental and ab ini- tio analysis. Journal of Materials Chemistry C 2014, 2 (44), 9416-9424, DOI: 10.1039/C4TC01293C.

[10] Biswas, M.; Libera, J. A.; Darling, S. B.; Elam, J. W. Kinetics for the Sequential Infiltration Synthesis of Alumina in Poly(methyl methacrylate): An Infrared Spectroscopic Study. The Journal of Physical Chemistry C 2015, 119 (26), 14585-14592, DOI: 10.1021/jp511939j.

[11] Hill, G. T.; Lee, D. T.; Williams, P. S.; Needham, C. D.; Dandley, E. C.; Oldham, C. J.; Parsons, G. N. Insight on the Sequential Vapor Infiltration Mechanisms of Trimethylaluminum with Poly(methyl methacrylate), Poly(vinylpyrrolidone), and Poly(acrylic acid). The Journal of Physical Chemistry C 2019, 123 (26), 16146-16152, DOI: 10.1021/acs.jpcc.9b02153.

[12] Gong, B.; Parsons, G. N. Quantitative in situ infrared analysis of reactions between trimethylaluminum and polymers during $\mathrm{Al}-2 \mathrm{O}_{3}$ atomic layer deposition. Journal of Materials Chemistry 2012, 22 (31), 15672-15682, DOI: 10.1039/C2JM32343E.

[13] Pereira, A. P.; Silva, M.; Jr, É.; Paula, A.; Tommasini, F. Processing and Characterization of PET Composites Reinforced With Geopolymer Concrete Waste. Materials Research 2017, DOI: 10.1590/1980-5373-mr-2017-0734.

[14] Paszkiewicz, S.; Szymczyk, A.; Pawlikowska, D.; Irska, I.; Taraghi, I.; Pilawka, R.; Gu, J.; Li, X.; Tu, Y.; Piesowicz, E. Synthesis and characterization of poly(ethylene terephthalateco-1,4-cyclohexanedimethylene terephtlatate)block-poly(tetramethylene oxide) copolymers. RSC Advances 2017, 7 (66), 41745-41754, DOI: 10.1039/C7RA07172H.

[15] Chen, Z.; Hay, J. N.; Jenkins, M. J. The thermal analysis of poly(ethylene terephthalate) by FTIR spectroscopy. Thermochimica Acta 2013, 552, 123-130, DOI: https://doi.org/10.1016/j.tca.2012.11.002.

[16] Latko-Durałek, P.; Dydek, K.; Boczkowska, A. Thermal, Rheological and Mechanical Properties of PETG/rPETG Blends. Journal of Polymers and the Environment 2019, 27 (11), 2600-2606, DOI: $10.1007 / \mathrm{s} 10924-019-01544-6$.

[17] Beamson, G.; Briggs, D. High Resolution XPS of Organic Polymers: The Scienta ESCA300 Database. Journal of Chemical Education 1993, 70 (1), A25, DOI: 10.1021/ed070pA25.5. 